\title{
Efficiency of Surber net under different substrate and flow conditions: insights for macroinvertebrates sampling and river biomonitoring
}

\author{
Alberto Doretto ${ }^{1,4, *}$, Tiziano $\mathrm{Bo}^{2}$, Francesca Bona ${ }^{3,4}$ and Stefano Fenoglio ${ }^{3,4}$ \\ ${ }^{1}$ DISIT, University of Piemonte Orientale, Viale Teresa Michel 25, 15121, Alessandria, Italy \\ 2 Naturastaff, Via Lunga 11, 14040, Mongardino, Italy \\ 3 DBIOS, University of Torino, Via Accedemia Albertina 13, 10123, Torino, Italy \\ ${ }^{4}$ ALPSTREAM - Alpine Stream Research Center, 12030, Ostana, Italy
}

Received: 13 November 2019 / Accepted: 13 January 2020

\begin{abstract}
In biomonitoring great attention has been paid on the selection of the best indices and metrics, often neglecting a simple but fundamental aspect: how reliable are the sampling methodologies? We tested the efficiency of the Surber net in collecting stream macroinvertebrates by comparing two samples collected consecutively on the same plot. We found that substrate particle size and water depth and velocity significantly affected sampling efficiency, especially regarding the total taxa richness, EPT (Ephemeroptera, Plecoptera and Trichoptera) richness and density. This study therefore provides useful insights to collect stream macroinvertebrates using the Surber net under different near-bed conditions.
\end{abstract}

Keywords: Diversity / stream / benthic invertebrates / collection / metrics

Résumé - Efficacité du filet Surber dans différentes conditions de substrat et de débit : perspectives pour l'échantillonnage des macroinvertébrés et la biosurveillance des rivières. Dans le domaine de la biosurveillance, une grande attention a été accordée à la sélection des meilleurs indices et mesures, en négligeant souvent un aspect simple mais fondamental : quelle est la fiabilité des méthodes d'échantillonnage ? Nous avons testé l'efficacité du filet Surber pour la collecte de macroinvertébrés en rivière en comparant deux échantillons prélevés consécutivement sur la même parcelle. Nous avons constaté que la taille des particules du substrat ainsi que la profondeur et la vitesse de l'eau avaient une incidence importante sur l'efficacité de l'échantillonnage, surtout en ce qui concerne la richesse totale en taxons, la richesse et la densité des EPT (éphéméroptères, plécoptères et trichoptères). Cette étude fournit donc des renseignements utiles pour recueillir des macroinvertébrés de cours d'eau à l'aide du filet Surber dans différentes conditions au niveau du substrat.

Mots clés : Diversité / cours d'eau / invertébrés benthiques / échantillonnage / métrique

\section{Introduction}

Sampling effort is one of the most crucial stages of ecological studies, which affects the interpretation of the results as well as the achievements of a research project or a monitoring plan. For example, the evaluation of the ecological status of water bodies is a primary goal in river ecology. This often depends on the correct calculation of biomonitoring indices which, in turn, can be influenced by the sampling effort (Everall et al., 2017). Data collection, therefore, can have

\footnotetext{
*Corresponding author: alberto.doretto@uniupo.it
}

important repercussions on the analysis, ultimately dictating management and/or restoration actions.

Benthic macroinvertebrates are one of the most studied biological groups for lotic ecosystems, often included in river biomonitoring and assemblage ecology research. In particular, macroinvertebrates have a long tradition as bioindicators for running waters, and their use in monitoring programs is growing worldwide (Flotemersch et al., 2017; Merritt et al., 2017).

Different sampling devices have been proposed to collect macroinvertebrates in lotic ecosystems based on the river typology (wadeable or not-wadeable), experimental approach (qualitative or quantitative), and cost- and time-related aspects (Hauer and Resh, 2017). In fact, artificial substrates are usually 
employed in the deepest sections of rivers, where water depth does not allow safety conditions for operators. On the contrary, hand nets, like the D- or U-nets, are easier to use and widely employed on wadeable sections of rivers (Carter and Resh, 2001; Hughes and Peck, 2008). Among these devices, the Surber net (or Surber sampler) is one of the most commonly used methods for collecting benthic invertebrates. This tool consists of a squared net (mesh size typically 250 or $500 \mu \mathrm{m})$ with a metal frame that delineates a relatively consistent area of the river bottom and allows the quantitative collection of benthic organisms. This latter aspect makes the Surber net the official device for macroinvertebrates sampling according to the Water Framework Directive (2000/60) in some European countries (Böhmer et al., 2004; Bo et al., 2017).

Several studies have tested the performance of the Surber net and demonstrated that, in general, this sampling device is more efficient in collecting macroinvertebrates than others, such as Hess sampler, kick and hand nets (Storey et al., 1991; Ghani et al., 2016; Tubić et al., 2017) because it limits the accidental loss of individuals during the sampling operations.

Here we evaluated the reliability of the Surber net in collecting macroinvertebrates by comparing two consecutive samples collected on the same plot for a total of 156 different samples. Differences in the relative number of benthic taxa and individuals collected by the first sample, compared to the cumulative sample (first + second sample), were statistically tested in relation to near-bed conditions (i.e. substrate size and water depth and velocity).

Benthic macroinvertebrates were sampled from 78 different plots within a single $130 \mathrm{~m}$ stream reach of the Bormida River (Northwestern Italy, latitude: $44^{\circ} 52^{\prime} 23.19^{\prime \prime}$, longitude: $8^{\circ} 36^{\prime} 12.84^{\prime \prime}$ ) on 17 and 18 October 2016. Plots were representative of the micro-habitat heterogeneity at the reach scale and were progressively numbered from down- to upstream. At each plot, two separate Surber samples were collected $\left(\right.$ area $\left.=0.05 \mathrm{~m}^{2}\right)$. The first one (hereafter sample A) was obtained by positioning the Surber net flush with the river bottom, with the opening against the current. By means of hands and feet benthic organisms were dislodged from the substrate within the metal frame of the net, and all the content was transferred into a labelled plastic jar and preserved with $90 \%$ ethanol. As soon as we removed the net, at the same exact location, we placed another identical Surber net to collect a second sample (hereafter sample B) following the same procedure. This operation was repeated for all the 78 plots within the river reach by the same operators, allowing the comparability among samples. Moreover, for each plot the water depth was measured using a meterstick, and substrate composition within the metal frame was visually assessed by estimating the percentage of boulders $(>256 \mathrm{~mm})$, cobbles $(256-64 \mathrm{~mm})$, gravel $(64-2 \mathrm{~mm})$ and fine sediment $(<2 \mathrm{~mm})$. Water velocity was visually classified according to one of the following categories: high $\left(>1 \mathrm{~m} \mathrm{~s}^{-1}\right)$, intermediate $\left(1-0.1 \mathrm{~m} \mathrm{~s}^{-1}\right)$, and low $\left(<0.1 \mathrm{~m} \mathrm{~s}^{-1}\right)$.

Samples were returned to the laboratory for sorting and systematic identification, which was performed to the lowest possible taxonomic level (i.e. species, genus, or family). A samples-per-taxa matrix was then created, and for each plot, a cumulative sample (hereafter sample C) was obtained by summing macroinvertebrates collected in the two separate samples (i.e. sample A + sample B). Taxa accumulation curves were generated separately for the $\mathrm{A}$ and $\mathrm{C}$ samples to visually check the representativeness of the data collection and differences between the first sample only (A) and the cumulative one (C). This statistical analysis was performed with the "specaccum" function in the vegan R package (Oksanen et al., 2017).

Five community metrics were calculated for each sample: total taxa richness, total abundance, EPT (Ephemeroptera, Plecoptera and Trichoptera) richness, EPT abundance and the Shannon index. These five metrics are routinely used in benthic ecology and are often included in several biomonitoring indices (Sánchez-Montoya et al., 2010; Bo et al., 2017, Burgazzi et al., 2018; Doretto et al., 2018). The proportions between the number of taxa, as well as the number of specimens collected, by sample A only and sample $\mathrm{C}$ were calculated. The same was done for EPT richness and abundance, while the Shannon index differences between the two samples were expressed as the arithmetical subtraction between the value of sample $\mathrm{C}$ and that of sample A.

Regression models were run to test for significant effects of the water velocity, depth, substrate size and their interactions on the selected community metrics. Generalized Linear Models with a binomial distribution were used for the proportion variables, while Linear Models were applied for the Shannon index. Water velocity was included as a categorical variable (i.e. three levels: high, intermediate and low), while the water depth and substrate size were included as continuous variables. For this analysis the percentages of each substrate class were used calculate the Substrate Index (SI; modified from Quinn and Hickey, 1994) according to the following formula:

$$
\begin{aligned}
\text { SI }= & 0.08 x \% \text { boulders }+0.065 x \% \text { cobbles } \\
& +0.045 x \% \text { gravel }+0.03 x \% \text { fine sediment }
\end{aligned}
$$

This index provides a measure of the coarseness of the substrate: it varies from $3(100 \%$ fine sediment) to $8(100 \%$ boulders).

Model selection was carried out according to the AIC criterion and the significance of each variable, including their interactions, was tested by the "aov" function. All the statistical analyses were carried out with the software $\mathrm{R}$ (R Core Team, 2017).

A total of 49318 invertebrates, belonging to 50 taxa were collected. On average, we found that the first sample (A) accounted for the 89 and $74 \%$ of the total taxa richness and total abundance, respectively, obtained by pooling together the two samples collected on the same plot. Similar percentages were also observed for the EPT richness and abundance: 87 and $79 \%$ respectively. On the contrary, the arithmetical difference in the Shannon index between the A and $\mathrm{C}$ samples ranged between -0.23 and +0.51 .

Taxa accumulation curves showed very similar trends between the $\mathrm{A}$ and $\mathrm{C}$ samples, but the total taxa richness obtained exclusively by the first Surber sample (A) was 46 out of 50 (Fig. 1). Interestingly, four benthic taxa, Lymnaeidae, Serratella ignita, Philopotamus sp. and Calopteryx sp., were missed by the first Surber sample and found only in the second 


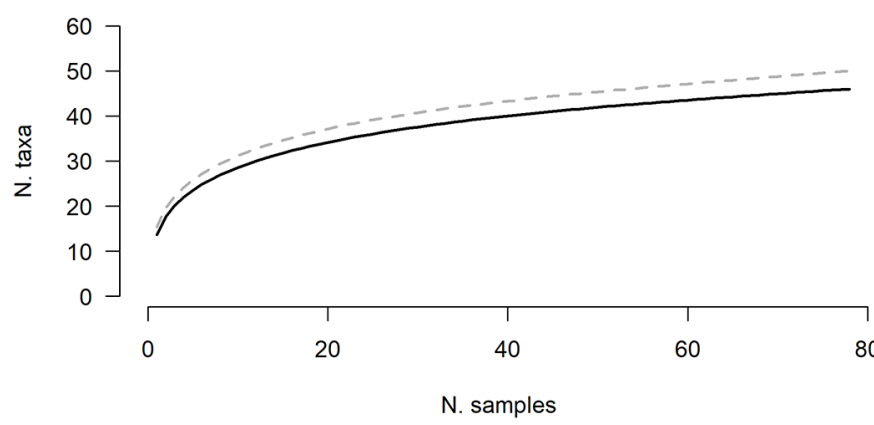

Fig. 1. Taxa accumulation curves based on the first sample only (black line) and the cumulative sample (grey dashed line).

sample. These taxa were represented by only one individual in this study.

When looking at the variation of the assemblage metrics in relation to the flow and substrate conditions, we found significant results for the taxa richness, EPT richness, and the EPT abundance (see below), while no statistical differences were observed for the total abundance of macroinvertebrates and Shannon index.

A significant effect of the interaction between the substrate size and water velocity was observed on the taxa richness $(P=0.015$; proportion of deviance explained $=13 \%)$. The proportion of taxa collected by the first Surber sample (A) significantly increased with the increase of the substrate size when the water velocity was high, whereas the opposite trend was found at low water velocity (Fig. 2A). On the contrary, the proportion of taxa collected by the sample $\mathrm{A}$ in comparison to the cumulative sample (C) did not vary with the substrate size under intermediate values of water velocity (Fig. 2A).

A significant effect of the interaction between water depth and velocity was found for EPT richness $(P=0.003$; proportion of deviance explained $=17.4 \%$ ). The proportion of EPT taxa collected by the first Surber sample slowly and markedly decreased with substrate size under high and low water velocity conditions, respectively (Fig. 2B). No significant variation in the proportion of EPT taxa was observed for intermediate values of water velocity (Fig. 2B).

The EPT abundance was significantly affected only by water velocity $(P=0.034$; proportion of deviance explained $=$ $12.5 \%$ ). The proportion of EPT invertebrates collected by sample A was significantly lower at low water velocity compared to intermediate or high conditions (Fig. 2C).

Finally, no significant effects of near-bed variables on the total abundance and Shannon index were found. However, the proportion of benthic individuals slightly increased along with water depth, while arithmetical differences in the Shannon index in relation to the substrate size were more pronounced at high water velocity.

Although the performance of the Surber net has already been evaluated in published studies, the majority of these compared its efficiency in relationship to other sampling techniques (Storey et al., 1991; Stark 1993; Ghani et al., 2016; Tubic et al., 2017). Here, the efficiency of the Surber net in collecting stream macroinvertebrates was tested by comparing two consecutive samples collected on the same plot, as done by some authors for other sampling devices (Bradley and Ormerod, 2002).
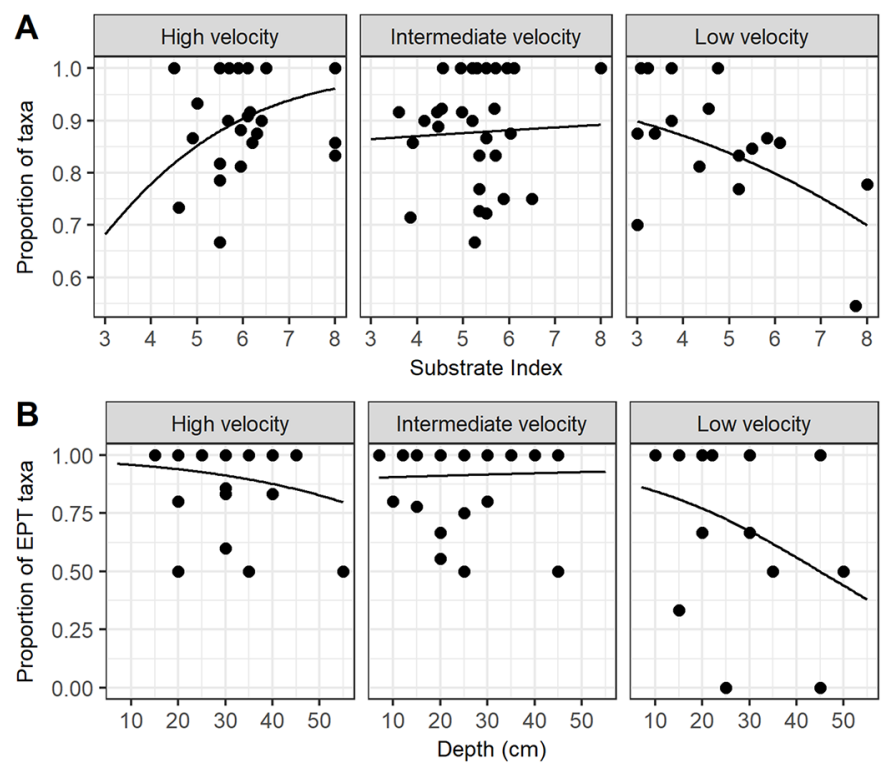

\section{C}

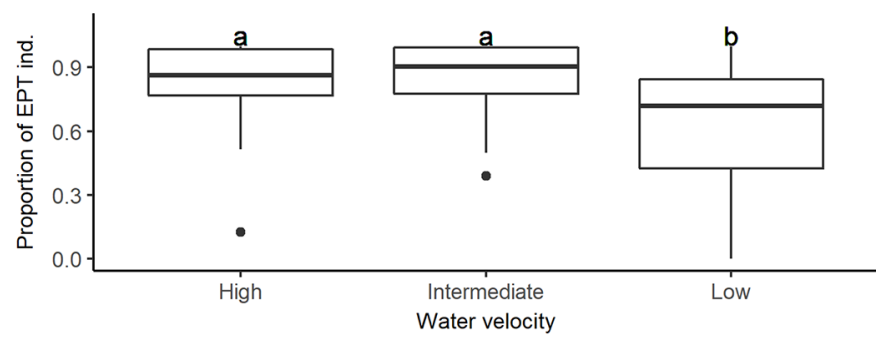

Fig. 2. Graphs represent the variation in the proportion of (A) total taxa richness and (B) EPT richness between the first Surber sample and the cumulative sample in relationship to the substrate index and water depth and velocity. Samples with identical values of the variables (i.e. the same proportion of taxa at the same depth) overlap in the graph. Boxplots (C) represent the proportion of EPT individuals in relationship to the water velocity: the vertical black line indicates the median, while the lower and upper edges of the boxes represent the first and the third quartiles respectively.

In general, our results confirm that the Surber net is a reliable and efficient device: the first Surber sample was able to collect between $74-89 \%$ of the benthic taxa, essentially providing the same amount of information that was obtained by doubling the sampling effort (i.e. cumulative sample). These findings could be of direct practical interest, especially when time and cost-related aspects motivate the choice of sampling methods. However, four benthic taxa, represented by only one individual, were obtained only in the second sample, and this is important information for species inventories (Storey et al., 1991), although it may be context-dependent. Further studies with more replicates are needed. Similar results were found by Li et al. (2001) in Oregon streams where taxa accumulation curves did not reach an asymptote even after 50-60 Surber samples due to rare taxa. Overall, these findings stress the sensitivity of less abundant taxa to sampling effort.

We found that near-bed conditions at the microhabitat scale strongly affected the efficiency of the Surber sampler. In particular, water velocity, alone or in combination with 
substrate and depth, significantly affected the number of macroinvertebrate taxa and/or specimens collected, acting as a crucial variable during sampling procedures. As expected, water velocity proportionally facilitates the collection of macroinvertebrates by enhancing their removal from the substrate, although substrate size and depth can interfere with this process.

Therefore, this study provides useful insight for sampling stream macroinvertebrates using the Surber net, especially when data are collected for river biomonitoring and biodiversity assessments, as pointed out by other authors (Stark, 1993; Everall et al., 2017). Because multihabitat sampling methods often use substrate composition and flow conditions to allocate different replicates at the reach scale (Bo et al., 2017), our findings provide evidence on the efficiency of the Surber net in collecting macroinvertebrates under different flow and substrate conditions.

Acknowledgements. The authors are very grateful to Massimo Pessino and Elena Piano for their assistance in field collection and statistical analysis respectively, and also to the anonymous reviewers for their useful comments. Courtney E. Larson is particularly acknowledged for her help in the linguistic revision. This work was supported by the University of Piemonte Orientale funds (S. Fenoglio).

\section{References}

Bo T, Doretto A, Laini A, Bona F, Fenoglio S. 2017. Biomonitoring with macroinvertebrate communities in Italy: what happened to our past and what's the future? J Limnol 76: 21-28.

Böhmer J, Rawer-Jost C, Zenker A. et al. 2004. Assessing streams in Germany with benthic invertebrates: Development of a multimetric invertebrate based assessment system. Limnologica 34: 416-432.

Bradley DC, Ormerod, SJ. 2002. Evaluating the precision of kicksampling in upland streams for assessments of long-term change: the effects of sampling effort, habitat and rarity. Arch Hydrobiol 155: 199-221.

Burgazzi G, Guareschi S, Laini A. 2018. The role of small-scale spatial location on macroinvertebrate community in an intermittent stream. Limnetica 37: 319-340.

Carter JL, Resh VH. 2001. After site selection and before data analysis: sampling, sorting, and laboratory procedures used in stream benthic macroinvertebrate monitoring programs by USA state agencies. JN Am Benthol Soc 20: 658-682.

Doretto A, Piano E, Bona F, Fenoglio S. 2018. How to assess the impact of fine sediments on the macroinvertebrate communities of alpine streams? A selection of the best metrics. Ecol Indic 84: 60-69.
Everall NC, Johnson MF, Wood P, Farmer A, Wilby RL, Measham N. 2017. Comparability of macroinvertebrate biomonitoring indices of river health derived from semi-quantitative and quantitative methodologies. Ecol Indic 78: 437-448.

Flotemersch JE, Saavedra JM, Laffitte L, Laurenzano B, Bonardi MA, Blocksom KA. 2017. Benthic macroinvertebrate field sampling effort required to produce a sample adequate for the assessment of rivers and streams of Neuquén Province, Argentina. Limnologica 65: 55-60.

Ghani WMHWA, Rawi CSM, Hamid SA, Al-Shami SA. 2016. Efficiency of different sampling tools for aquatic macroinvertebrate collections in Malaysian streams. Trop Life Sci Res 27: $115-133$.

Hauer FR, Resh VH. 2017. Macroinvertebrates. In Hauer FR, Lamberti GA eds. Methods in Stream Ecology. Cambridge: Academic Press, 297-320.

Hughes RM, Peck DV. 2008. Acquiring data for large aquatic resource surveys: the art of compromise among science, logistics, and reality. $J N$ Am Benthol Soc 27: 837-859.

Li J, Herlihy A, Gerth W. et al. 2001. Variability in stream macroinvertebrates at multiple spatial scales. Freshw Biol 46: 87-97.

Merritt RW, Fenoglio S, Cummins KW. 2017. Promoting a functional macroinvertebrate approach in the biomonitoring of Italian lotic systems. J Limnol 76: 5-8.

Oksanen J, Blanchet FG, Friendly M. et al. 2017. Vegan: Community Ecology Package. R package version 2. 42.

Quinn JM, Hickey CW. 1994. Hydraulic parameters and benthic invertebrate distributions in two gravel-bed New Zealand rivers. Freshw Biol 32: 489-500.

R Core Team. 2017. R: A language and environment for statistical computing. R Foundation for Statistical Computing, Vienna, Austria.

Sánchez-Montoya MM, Vidal-Abarca MR, Suárez ML. 2010. Comparing the sensitivity of diverse macroinvertebrate metrics to a multiple stressor gradient in Mediterranean streams and its influence on the assessment of ecological status. Ecol Indic 10: 896-904.

Stark JD. 1993. Performance of the Macroinvertebrate Community Index: effects of sampling method, sample replication, water depth, current velocity, and substratum on index values. New Zeal J Mar Fresh 27: 463-478.

Storey AW, Edward DHD, Gazey P. 1991. Surber and kick sampling: a comparison for the assessment of macroinvertebrate community structure in streams of south-western Australia. Hydrobiologia 211: 111-121.

Tubić B, Popović N, Raković M, Petrovic A, Simić V, Paunović M, 2017. Comparison of the effectiveness of kick and sweep hand net and Surber net sampling techniques used for collecting aquatic macroinvertebrate samples. Arch Biol Sci 69: 233-238.

Cite this article as: Doretto A, Bo T, Bona F, Fenoglio S. 2020. Efficiency of Surber net under different substrate and flow conditions: insights for macroinvertebrates sampling and river biomonitoring. Knowl. Manag. Aquat. Ecosyst., 421, 10. 